attacks usually occurs by early childhood ${ }^{2}$; occasionally the episodes may persist into early adult life.

The most important aspect of treatment is to explain the condition to parents and to reassure them that it is not epilepsy and that the prognosis is good. Atropine has been advocated to prevent the vagal hypersensitivity in those children with frequent, persistent attacks or when parents remain concerned. ${ }^{39}$ Although atropine may be effective, ${ }^{9}$ its pharmacodynamic properties indicate that dosing may need to be frequent, which increases the risk of overdose. Drug treatment has been unnecessary in my and at least one other author's experience. ${ }^{10}$

"Reflex anoxic seizure" is not universally accepted as the most appropriate term for this phenomenon ${ }^{112}$ because the word seizure in many medical (and non-medical) minds is synonymous with epilepsy. ${ }^{13}$ As the condition is often misdiagnosed as epilepsy (this accounted for $15 \%$ of misdiagnoses in one series ${ }^{7}$ ) the description of the attacks as seizures should perhaps be avoided to prevent any additional confusion or concern. ${ }^{13}$ Parents often remember only the word seizure and not what it means, no matter how careful the explanation. ${ }^{1314}$ Because of this, and the suggested mechanism, these attacks have also been called white or type 2 breath holding attacks ${ }^{10}$ (in contrast to the blue or type 1 breath holding attacks), although the primary event is not one of breath holding. Other names include reflex anoxic cerebral seizures with white syncope, ${ }^{3}$ which is too verbose a label, and pallid infantile syncope ${ }^{2}$ or pallid syncopal attacks, which is probably the most popular alternative. ${ }^{113}$ Pallor, however, is not a constant feature..$^{12}$

An awareness of the condition and an accurate history are crucial to both diagnosis and "treatment." This may help to resolve some of the concern that has been expressed recently in the national press ${ }^{15}$ and that has prompted the inception of a self help group for "affected" families.

RICHARD E APPLETON Consultant paediatric neurologist

The Roald Dahl EEG Unit,

Royal Liverpool Children's NHS Trust (Alder Hey),

Liverpool L12 2AP

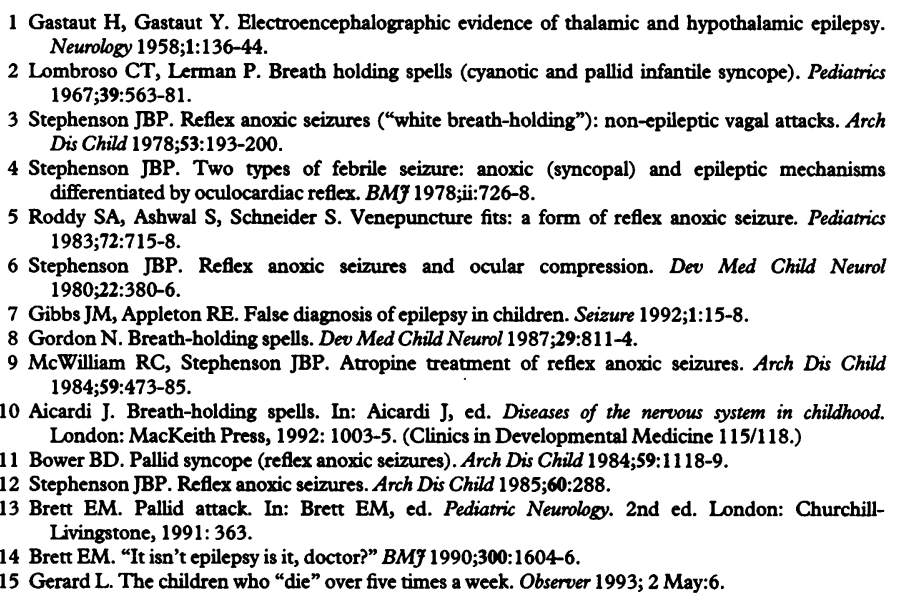

\title{
Who needs dual chamber pacing?
}

\section{The British guidelines probably exaggerate the needs; proper studies should be done}

Traditional cardiac pacing transformed the lives of a generation of patients with heart block. Victims of Stokes Adams attacks regained their confidence and their driving licences. Those with fatigue and heart failure due to bradycardia were improved. Their pacing systems were simple: a single transvenous electrode positioned in the right ventricle, which was attached to a generator implanted subcutaneously. It paced the heart at 70 beats per minute and was inhibited if the patient's own heart rate exceeded that speed.

These patients fared well. But experience over the past 15 years suggests that they might have fared even better with a more complex system. The addition of an atrial electrode to sense or pace the atria (or do both), linked to a dual chamber pacemaker that then triggers ventricular depolarisation, has many theoretical and practical advantages. Firstly, restoring atrial transport improves stroke volume; secondly, heart rate can respond to effort and further improve exercise capacity ${ }^{1}$ provided that sinus node function is normal; thirdly, compared with single chamber systems it may reduce the risk of the subsequent development of atrial fibrillation ${ }^{2}$ and systemic embolism ${ }^{3}$; fourthly, the pacemaker syndrome-a vague collection of symptoms due to the atria and ventricles contracting asynchronously-is abolished ${ }^{4}$; and lastly, dual chamber pacing is now reliable and effective over years. ${ }^{5}$

The only definite contraindication to dual chamber pacing is established atrial fibrillation, but even then a heart rate response to exercise can be achieved in those with a bradycardia by implanting a generator that senses a bodily changefor example, movement - and accelerates accordingly. Dual chamber and rate response devices are but two of the more spectacular developments in pacing technology. These and others, such as the ability to reprogramme the generator after implantation, have led to such an array of alternatives that in 1991 two groups of experts published guidelines for pacemaker implants, taking into account both the technical advances and the widening indications for this form of treatment. Both the British ${ }^{6}$ and North American ${ }^{7}$ reports recommend the greater use of more complex pacemakers; the document from the British Pacing and Electrophysiology Group contains the suggestion that "the atrium should be paced/sensed unless contra-indicated." This has financial consequences, as the authors predicted.

A dual chamber pacing system costs almost three times as much as a simple ventricular system-about $£ 2100$ compared with $£ 750$ (1991 prices). Wholesale implementation of the British recommendations would increase pacing budgets by an estimated $75 \%$ to $94 \%,{ }^{9}$ although this has been challenged..$^{10}$ The expense does not stop there, however: dual chamber systems are more difficult to insert; follow up appointments take longer; and pacemaker malfunction is more difficult to detect, placing greater demands on technical staff. In addition, the generators will probably not last as long.

The working party of the British Pacing and Electrophysiology Group and others ${ }^{11}$ have argued that costs should not inhibit the promulgation of an ideal pacing practice. Quite so, but a more serious objection is that all the guidelines ${ }^{6711}$ ignore patients and their clinical needs; the recommendations deal solely with conduction systems and their defects.

The average age of the 700 patients who received new pacemaker implants at this hospital in 1990-1 was 76 years; $82 \%$ of the patients from St George's Hospital, London, were over $65 .^{8}$ Most pacemaker patients are elderly. Their exercise 
tolerance is often limited by locomotor rather than cardiovascular disability. Not many want the slightly increased walking time on the treadmill that a dual chamber system offers. ${ }^{1}$

Another clinical issue is that some patients remain in sinus rhythm with intact atrioventricular conduction and need their pacemakers only on very rare occasions when their own conduction falters: they hardly need a dual chamber system. A further drawback to the recommendations is that they are based on data that may be politely described as observational, rather than on the results of prospective randomised trials in defined groups of patients.

In 1992 , one quarter of the 10000 or so pacemakers that were implanted in Britain were dual chamber. The use of such systems varied from $5 \%$ to $75 \%$ in those centres implanting at least 50 units a year. ${ }^{12}$ This remarkable variation cannot be solely due to referral patterns, although some centres specialise in conditions such as the vasovagal syndromes, for which dual chamber pacing is thought to be essential. Clearly the guidelines are being tempered by local circumstances to a remarkable degree.

Guidelines drawn up by experts offer a counsel of perfection that may be inappropriate for day to day practice. Most cardiac centres will be implanting dual chamber systems into patients who are judged to need atrial activity on clinical grounds-that is, those with symptoms on effort and those with heart failure who are not otherwise incapacitated. Directors of public health in purchasing authorities should examine local practices with curiosity and await the results of the various trials of single versus dual chamber pacing that are now underway.

M C PETCH

Papworth Hospital,

Papworth Everard,

Cambridge CB3 8RE

1 Kruse I, Arnman K, Conradson T, Ryden LA. A comparison of the acute and long-term haemodynamic effects of ventricular inhibited and atrial synchronous ventricular inhibited pacing. Circulation 1981;65:846-55.

2 Hesselson AB, Pasonnet V, Bernstein AD, Bonavita GJ. Deleterious effects of long-term singlechamber ventricular pacing in patients with sick sinus syndrome: the hidden benefits of dualchamber pacing. 9 Am Coll Cardiol 1992;197:1542-9.

S chamber pacing. F Am Coll Cardiol 1992;197:1542-9.

4 Travill CM, Sutton M. Pacemaker syndrome: an iatrogenic condition. Br Heart f 1992;68:163-6.

5 Gross JN, Moser S, Benedek ZM, Andrews C, Furman S. DDD pacing mode survival in patients Gross JN, Moser S, Benedek ZM, Andrews C, Furman S. DDD pacin
with a dual-chamber pacemaker. $f$ Am Coll Cardiol 1992;19:1536-41.

with a dual-chamber pacemaker. $f$ Am Coll Cardiol 1992;19:1536-41.
6 Clarke M, Sutton R, Ward D, Camm AH, Rickards A, Ingram A, et al. Recommendations for pacemaker prescription for symptomatic bradycardia. Br Heart 91991 ; 66:185-91.

7 ACC/AHA Task Force. Guidelines for implantation of cardiac pacemakers and antiarthythmi devices. I Am Coll Cantiol 1991;18:1-13.

8 De Belder MA, Linker NJ, Jones S, Camm AH, Ward DE. Cost implications of the British pacing and electrophysiology group's recommendations for pacing. BMF 1992;305:861-5.

Ray SG, Girrith MJ, Jamieson S, Bexton RS, Gold RG. Impact of the recommendations of the British Pacing and Electrophysioloog Group on pacemaker prescription and on the immediate costs of pacing in the Northern Region. Br Hean $f$ 1992;68:531-4.

10 Channon KM, Cripps RR, Ormerod O. Recommendations for pacing. BMF 1992;305:1431.

11 Nathan AW, Davies DW. Is VVI pacing outmoded? Br Heart I 1992;67:285-8.

12 British Pacing and Electrophysiology Group. BPEG Data Bulletin 1993; March.

\section{Doctors and markets}

\section{Private medicine is a long way from being a perfect market}

Markets when they work perfectly are much the most efficient way to distribute resources. In the widget market beloved of microeconomists the right numbers of the right quality are produced at the optimum price. In contrast, in the planned Soviet style economy many goods are not available at all, some are grossly oversupplied, most are of poor quality, and many are overpriced: resources are used very inefficiently. It is the astonishing efficiency of the perfect market-beautifully analysed by Adam Smith over 200 years ago-that causes so many people to be so fervent about markets and to want them introduced into health care, prisons, and every other sector.

Unfortunately, few if any markets are perfect. The conditions of the perfect market are that buyers and sellers are too small to move the market price by themselves; that sellers have free entry to, and exit from, the market; and that buyers have perfect information about the seller's goods. These conditions are rarely met, and one potent reason why they are not is that sellers will do everything they can to fix a price higher than a perfect market would dictate. Adam Smith wrote in the Wealth of Nations: "People of the same trade seldom meet together, even for merriment and diversion, but the conversation ends in a conspiracy against the public, or in some contrivance to raise prices." One legitimate role of government is to try to ensure that prices are not fixed and that markets operate as near perfectly as possible. This is where antitrust legislation begins, and that is why the Monopolies and Mergers Commission is currently investigating private medical services.

It began its inquiry last September because it believed that the BMA's guidelines on consultant fees, which were first introduced in 1989, might be restricting competition. The commission has now decided that a "complex monopoly" does exist, but it has not decided what remedy to apply. Last week, however, it wrote to all interested parties (including all NHS consultants), sharing the data it has collected and asking for reactions to its work so far and for ideas on what remedies might be applied.

Private medical practice in Britain, which in total the commission estimates to be a business of $£ 9215 \mathrm{~m}$ in 1992 , is far from being a perfect market. Firstly, doctors have to mount substantial barriers to enter the market, particularly as private practice is mostly restricted to consultants. The commission notes in passing that the acceptance in Britain of European Community specialist qualifications could have a considerable effect on the supply of consultants. We are left to infer that this may substantially reduce the prices they can charge. Secondly, the buyers in this market have far from perfect information: rarely have they much idea of the quality of the services they are buying, and often they don't even know the price until they have bought. Buyers tend to rely on general practitioners to guide them, and the commission notes that general practitioners "unwittingly present a barrier to competition" because they don't know about new consultants and their prices. The commission recommended in 1989 that consultants should advertise to general practitioners, but the remedies it is now considering to improve information are to require consultants to make their charges known to patients at the earliest possible opportunity and to let all general practitioners in their area know their charges.

But it's the third impediment to a perfect market-the fact that some sellers might together be able to affect the pricethat most concerns the commission at the moment. This is what started it on the inquiry, and it has now gathered data that 9500 consultants (out of 17000 in the NHS, 2200 in the medical schools, and 6000 who are retired but still in private practice) supply $50 \%$ or more of their services at charges within $2 \%$ of those suggested in the BMA's guidelines or in 